\title{
The 2019 Young Innovators of Cellular and Molecular Bioengineering
}

We are pleased to present to you this year's twelve Young Innovators of Cellular and Molecular Bioengineering, whose original research is featured in this October issue. This current issue represents the sixth year of this extraordinary program, and with five former classes of Young Innovators, it is a convenient time to take stock of this accomplished group that now includes 68 Innovators among its numbers. The 56 previously published papers have been downloaded 32,700 times and cited 502 times, for per paper averages of 584 and 9.0, respectively. At the time of this writing, a remarkable $85.3 \%$ of the Young Innovators from 2014 to 2016 have become tenured already, with four authors reaching the rank of full professor so far. Two Young Innovators serve as associate department chairs, and 10 hold named, endowed titles. Of the 56 Young Innovators from 2014 to 2018, 58.9\% have received the prestigious CAREER Award from the National Science Foundation. This group has received 7 NIH New Innovator Awards, 2 NIH Trailblazer Awards, and two Presidential Early Career Awards in Science and Engineering (PECASE). Seven of our Young Innovators have been inducted as Fellows of the American Institute of Medical and Biological Engineering (AIMBE). In $2016 \mathrm{CMBE}$ started to award two annual journal awards, a Most Downloaded Article, and an Editors' Choice Award. Of the three Editors' Choice Awards announced prior to 2019, one went to a Young Innovator paper, and one to a regular article from a former Young Innovator. Three of our Young Innovators have come from Canada, and one from outside the university setting. Historically, $42.7 \%$ of our Young Innovators have been women, and $10.3 \%$ underrepresented minorities. These are encouraging numbers compared to the overall demographics of tenure-track engineering faculty nationwide, but there is still progress to be made.

All potential authors who hold the rank of Assistant Professor (or equivalent) at the time of nomination are eligible for selection, and while many of the authors are active members of the Biomedical Engineering Society (BMES), membership in BMES is not a requirement for inclusion. As in past years, awardees will present the papers in this issue in a special, two-part invited platform session on Friday, October 18 at the 2019 Annual Meeting of BMES in Philadelphia, at 8 am and $1: 15 \mathrm{pm}$ in the Terrace Ballroom $2-3$ of the Pennsylvania Convention Center. The articles in this issue represent some of the most innovative and impactful bioengineering studies carried out by junior faculty in our field. Seven of this year's 12 Young Innovators are women, and all are being recognized as rising stars in their field.

Six of this year's Young Innovator articles are focused on nano- and microscale particles and technologies designed for drug and gene delivery, or to probe microscale mechanics. Ashish Kulkarni and coworkers present drug loaded nanotherapeutics to modulate immune cell function. Juliane Nguyen describes an approach of using drug loaded nanoplexes to polarize macrophages for the purpose of suppressing tumor growth. James Dahlman and coworkers demonstrate the ability to differentially target different cell types in the liver via lipid nanoparticles for mRNA delivery. The team of Stephanie Seidlits presents an injectable hydrogel scaffold with a porous microstructure designed for gene delivery applications. Weiqiang Chen and colleagues examine the single-cell mechanical properties and allostasis of cells using a combined FRET and ultrasound tweezer approach. The team of John Wilson shows nanoparticles complexed with therapeutic siRNA that can be loaded into and then released from PLGA microparticle depots.

Six of our featured papers explore new facets of tissue engineering and biomechanics. Work from Ronke Olabisi demonstrates how a mixture of insulin secreting cells and mesenchymal stem cells delivered using a synthetic biomaterial scaffold promoted rapid healing of skin wounds. An interesting study from Sara Nunes de Vasconcelos at the University of Toronto concluded that Type 1 diabetes inhibits vascularization of engineered tissues and this effect could be reversed by supplementing these constructs with hepatocyte growth factor. Kimberly Stroka and her colleagues at the University of Maryland investigate how tumors invade the central nervous system using a novel biomimetic model of the blood-brain barrier, providing novel insights into their model of migration. Sarah Calve's contribution focuses on the development of novel tools, in this case the use of the non-canonical amino acid azidohomoalanine, to study the dynamics of protein expression in the different tissues present in developing mouse embryos. Rouging Zhao's group at the University of Buffalo presents a novel model of lung tissue that undergoes cyclic stretching to mimic breathing, and then validate this microtissue model by 
showing its response to FDA approved drugs for treating fibrosis.

In this sixth year of the CMBE Young Innovators program, we thank all of the former co-editors for their leadership and service, without which none of this would be possible: Michael King, David Mooney, Cynthia Reinhart-King, Nicholas Peppas, Christine Schmidt, Tejal Desai, Alyssa Panitch, Richard Waugh, William Bentley, Lola Eniola-Adefeso, and Stephanie Willerth.

We hope that you will enjoy reading this impressive collection of research articles and that you will encourage your eligible colleagues to nominate themselves for next year's CMBE Young Innovator competition. Self-nominations are due by November 8 , 2019, with selected authors notified by December 13, 2019, and full manuscripts due by February 14, 2020. Interested researchers who hold a position at the rank of Assistant Professor (or equivalent) are invited to submit a 250-word structured abstract and an NIHstyle biosketch to Editor-in-Chief Michael King at mike.king@vanderbilt.edu. You are invited to engage with us via social media on Twitter (www.twitter.com/ CMBEjournal) and Facebook (www.facebook.com/ CMBEjournal). We hope to see you in Philadelphia at the 2019 BMES Annual Meeting, at the $2020 \mathrm{CMBE}$ Conference in Puerto Rico, and online!

Michael R. King

Department of Biomedical Engineering

Vanderbilt University, 5824 Stevenson Center,

Nashville, TN 37235, USA

Electronic mail: mike.king@vanderbilt.edu

\section{StePhanie Willerth}

Department of Mechanical Engineering and Division of Medical Science, University of Victoria, Engineering Office Wing, Room 513, Victoria, BC, Canada

Electronic mail: willerth@uvic.ca 